\title{
As Políticas Curriculares que se desdobram nos espaços da Escola e na Formação de Professores
}

\author{
Aparecida Garcia Pacheco Gabriel ${ }^{1}$; Eduardo José Freire ${ }^{2}$; Sidney da Silva Chaves ${ }^{3}$;
} Marlize Reffatti Zinelli ${ }^{4}$; Marcelino de Jesus ${ }^{5}$;Mariana Emídio Oliveira Ribeiro ${ }^{6}$

\begin{abstract}
Resumo: O presente trabalho tem por finalidade promover reflexões e questionamentos a partir de um estudo de revisão bibliográfica sobre as Políticas Públicas Educacionais. O referido estudo teve por foco as problemáticas das políticas públicas educacionais criadas pela sociedade na modernidade e pós-modernidade, que,por sua vez, influenciam a formação e o papel do educador. As políticas curriculares constituem uma inquietação expressiva para as autoridades governamentais, gestores, formadores e professores que precisam implementar um currículo que tenha significado para os educandos. Políticas que são elaboradas sem a colaboração dos diversos sujeitos do processo educativo têm menores chances de serem abraçadas pelas escolas. Muitos dos pesquisadores que são contratados para gestarem as reformas e as propostas curriculares estão muito longe das práticas escolares e dos alunos contemporâneos.Os saberes da experiência dos professores são construídos na prática e validados pela prática. Portanto esses profissionais devem ser respeitados em suas condições de produtores de conhecimentos e não como meros executores de políticas.A construção curricular precisa ser dinâmica, participativa, flexível para que seus significados sejam sempre renovados para atender os anseios dos sujeitos do processo educativo e da sociedade. Autores como Brandão (2008), Formosinho (2007), Pacheco (2003 e Tardife (2012) fazem parte do quadro teórico, contribuindo para destacar que, nesse processo de conferir maior coerência e efetividade às políticas públicas curriculares, é necessário, também, intensificar forças na educação para envolver a família e a comunidade na escola, fortalecer o uso de didáticas participativas, ampliar a oferta de espaços físicos que possibilitem múltiplas aprendizagens, aprimorar o trabalho cooperativo, entre outras.
\end{abstract}

Palavras chave: Políticas Curriculares, Espaço Escolar, Pós-Modernidade.

\section{The Curriculum Policies that are revealed in the spaces of the School and Teacher Training}

\begin{abstract}
The present work has the purpose of promoting reflections and questions based on a bibliographic review study on Public Educational Policies. The study focused on the problems of public education policies created by society in modernity and postmodernity, which in turn influence the formation and role of the educator.Curricular policies are a major concern for government authorities, managers, trainers and teachers who need to implement a curriculum that has meaning for learners.Policies that are elaborated without the collaboration of the diverse subjects of the educative process have less chances of being embraced by the schools.Many of the researchers who are hired to carry out reforms and curriculum proposals are a long way from school practices and contemporary students.The knowledge of teacher experience are built in practice and validated by practice.Therefore, these professionals must be respected in their conditions as producers of knowledge and not as mere executors of policies.The curricular construction needs to be dynamic, participatory,
\end{abstract}

\footnotetext{
${ }^{1}$ Mestranda em PPGEnsino - Univates. Bolsista Taxista (PROSUP - CAPES). Atualmente é docente permanente na Faculdade de Alta Floresta-FAF. psicopacheco_1@ @otmail.com;

${ }^{2}$ Mestre em Educação pela Universidade Federal de Mato Grosso/ Membro do Grupo de Estudos e Pesquisa em Gestão e Financiamento da Educação Básica - GEPGFEB da UFMT. Mestrando em Contabilidade no Programa de Pós-Graduação da Fundação Instituto Capixaba de pesquisas em Contabilidade, Economia e Finanças - FUCAPE business school. freireej7@ hotmail.com;

${ }^{3}$ Mestrando em Educação pelo Instituto Educação Superior do Alto Araguaia - MT (IESA) conveniado pela Universidade Estácio de Sá (RJ) e Professor da Rede Estadual de Ensino de Mato Grosso e das Faculdades de Alta Floresta(FAF/FADAF). chaves_sidney@hotmail.com ${ }^{4}$ Mestre em Ciências Ambientais e Desenvolvimento Sustentável pela UuniversidadeTécnica de Comercialización y Desarrollo - UTCD (Universidad de Asunción-Paraguay) e Professora da Escola Técnica Estadual (ETE) e da Faculdade de Direito de Alta Floresta FADAF.Endereço eletrônico:lize.zinelli@outlook.com.br. lize.zinelli@outlook.com;

${ }^{5}$ Mestrando em Educação pelo Instituto Educação Superior do Alto Araguaia - MT (IESA) conveniado pela Universidade Estácio de Sá (RJ) e Professor da Escola Técnica Estadual (ETE) e das Faculdades de Alta Floresta(FAF/FADAF). marcelinodejesus@bol.com.br;

${ }^{6}$ Mestranda do Programa de Pós Graduação em Ambiente e Desenvolvimento (PPGAD) da Universidade do Vale do Taquari UNIVATES. Professora da Escola Técnica Estadual (ETE) e da Faculdade de Direito de Alta Floresta - FADAF e Faculdade de Alta Floresta-FAF. mariana_meo@hotmail.com
} 
flexible so that its meanings are always renewed to meet the expectations of the subjects of the educational process and society.Authors, such as Brandão (2008), Formosinho (2007), Pacheco (2003) and Tardif (2012) are part of the theoretical framework, contributing to highlight that, in this process of conferring greater coherence and effectiveness to public curricular policies. And that it is also necessary to intensify forces in education to involve the family and thecommunity in the school, to strengthen the use of participatory didactics, to increase the offer of physical spaces that allow multiple learning, to improve cooperative work, among others.

Keywords: Curricular Policies; School Space; Post-Modernity.

\section{Introdução}

Pretende-se, com este texto,promover reflexões, questionamentos a partir de um estudode revisão bibliográfica sobre as Políticas Públicas Educacionais.O referido estudo teve por foco as problemáticas das políticas públicas educacionais criadas pela sociedade na modernidade e pós-modernidade, que influenciam a formação e o papel do educador.Autores como Brandão (2008), Formosinho (2007), Pacheco (2003 e Tardife (2012) foram os autores base para esse estudo.

A concepção discutida nesse estudado foi de âmbito geral sobre as políticas públicas educacionais, assim, para essa oportunidade, delimitou-se a temática em políticas curriculares, que é uma inquietação expressiva para as autoridades governamentais, gestores, formadores e professores que precisam implementar um currículo que tenha significado para os educandos. Os gestores se veem com a missão de implementarem procedimentos e ideias curriculares quase sempre inquestionáveis da sua validade e efetividade para o espaço da escola.

Os professores colocam em prática a proposta curricular nem sempre compreendida por eles, e os alunos, passivamente, são os receptores dessas inovações curriculares. Os formadores de professores, que querem ser progressistas, procuram promover situações formativas para instrumentalizar os docentes para atenderem as demandas sociais, mas também para serem autônomos em seus propósitos, conscientes das contradições que emergem no contexto globalizado na atualidade.

Políticas que são elaboradas sem a colaboração dos diversos sujeitos do processo educativo têm menores chances de serem abraçadas pelas escolas. Muitos dos pesquisadores curriculares, quase sempre de âmbito das universidades, que são contratados para gestarem as 
reformas e as propostas curriculares, estão muito longe das práticas escolares e dos alunos contemporâneos.

Embora esses pesquisadores entendam das políticas públicas e sejam conhecedores do assunto, as suas multiplicidades de conhecimentos epistemológicos e paradigmas educacionais nem sempre estão em sintonia com as necessidades e realidades dos professores que estão na sala de aula. Os saberes dos professores e dos educandos precisam encontrar espaço de entrelaçamento com as políticas educacionais, tanto que Tardif (2012, p. 33) esclarece que os saberes dos professores são "plurais, estratégicos e desvalorizados". Os saberes docentes são provenientes de diferentes fontes. Esses saberes são os saberes "disciplinares, curriculares, profissionais (incluindo os da ciência da educação e da pedagogia) e experienciais".

Os professores, como autoridade responsável pela educação formal dos humanos, ainda são pouco ouvidos pelos dirigentes do sistema de ensino. Diante de tantas mudanças de paradigmas e de políticas públicas nesse país, o professor se perde em seus fazeres pedagógicos. Antes de entender bem uma política pública, já se tem outra entrando em cena. Assim, um dos dilemas que o professor enfrenta é a descontinuidade das políticas propostas.

Os saberes da experiência dos professores são construídos na prática e validados pela prática. Portanto, esses profissionais devem ser respeitados em suas condições de produtores de conhecimentos e não como meros executores de políticas que propõem modelos rígidos de currículo. As políticas precisam existir para organizar o processo educativo. Também devem considerar os saberes dos sujeitos do conhecimento, como atores racionais capazes de agir ativamente em todas as etapas de proposição e efetivação curricular.

A construção curricular precisa ser dinâmica, participativa, flexível para que seus significados sejam sempre renovados para atender os anseios dos sujeitos do processo educativo e da sociedade. Essas ideias estão presentes tanto na formação dos professores e nas proposições da maioria das políticas em vigência. Mas, com que intensidade esse ideário se efetiva nos espaços da escola? Como chegam na sala de aula? Atingem a formação do professor e, conseguintemente, o aluno com a qualidade social e ética que a educação requer?

Há, assim, a necessidade de se rever uma política pública curricular de forma contínua, planejada e a longo prazo, a fim de propiciar, nas escolas, competências para promover novas gestões escolares questionáveis, aulas voltadas para o mundo do trabalho, mecanismos de 
controle, tanto do processo de aprendizagem como dos resultados da aprendizagem, e uma educação empreendedora capaz de melhorar a sociedade brasileira como um todo.

\section{Contextualizando as Políticas Públicas Educacionais}

Para discutir a temática depolíticas curriculares e seus desdobramentos nos espaços da escola e da formação, faz-se necessário fazer uma breve contextualização de políticas curriculares e de políticas públicas educacionais.

Segundo o pensamento de Pacheco (2003), o currículo é inerente à educação como uma construção política, e parte do pressuposto que a escola é o veículo dessa atividade política. Porém, currículo não se reduz ser só a atividade politicamente institucionalizada na escola, mas a uma atividade do Estado. Existe toda uma organização com valores e pensamentos administrativos que são implementados por meio de leis, decretos, portarias, formando assim uma estrutura complexa e de difícil diálogo. Para Pacheco (2003, p.14), [...] “o currículo não pode ser separado nem do contexto amplo que o define no tempo e no espaço nem da organização escolar que o concretiza".

As políticas curriculares vêm assumindo um papel importante dentro das políticas educacionais no mundo contemporâneo, como parte do desenvolvimento econômico e social. As ações do Estado, através de suas normativas e formas de financiamentos, impõem o seu controle social ainda muito pouco entendido e questionado no âmbito da escola. Surgindo, assim, a necessidade de mais discussões entre os atores que efetivam a construção desse currículo dentro da escola. Para Pacheco (2003, p. 15), devemos analisar esse contexto olhando o macro e micropolíticas:

[...] nas macropolíticas, questiona-se os aspectos da fundamentação e organização dos poderes não só expressos nos documentos oficiais, mas também nos momentos de produção desses textos. Nesse sentido, reconhece-se o peso dos grupos socioeconômicos nas práticas de influenciacão e, ainda, o papel marcante da administração' [...] no plano das micropolíticas, aborda-se o lugar das escolas, dos professores e dos alunos na configuração da prática do currículo do currículo, lugares que nem sempre são controlados totalmente pela administração. 
Efetivamente as políticas curriculares são construídas em espaços administrativos e escolares que envolvem um contexto social de luta e de reconstrução de valores, fazendo assim necessária a intensificação da discussão da política curricular no espaço da escola, com foco no entendimento das políticas públicas educacionais geradas no Estado,da força que têm o seu poder e suas orientações. Neste sentido, são importantes os estudos sobre sua origem, das discussões de políticas educacionais e seu comando.

Segundo Pacheco (2003), as discussões são abrangentes, começando nas universidades, oriundas de pesquisas sobre o poder das comunidades. Posteriormente, passou a incorporar todos os níveis de ensino, emergindo, assim, as políticas públicas de educação como um campo de estudo. Atualmente as discussões se fazem presentes em cada nível de ensino, estendendo-se em sua oferta, em sua formação profissional, nas suas questões pedagógicas e na forma de financiamento. Tornando assim as políticas públicas educacionais um tema muito complexo e de difícil entendimento hoje no Brasil.

Diante do exposto, vemos que são as universidades as responsáveis, em seus cursos de licenciaturas e de formação inicial de professores, de constituírem mais tempo para a reflexão e discussões sobre as políticas públicas educacionais; que, ao interpretarem as normativas do Estado, também construam o pensamento crítico, otimista, empreendedor em seus alunos. Precisa-se formar alunos politicamente preparados para o desenvolvimento de uma sociedade humana, conforme propõe o Relatório para a UNESCO sobre a Comissão Internacional de Educação para o século XXI:

\footnotetext{
Ao terminar os seus trabalhos a Comissão faz, pois, questão de afirmar sua fé no papel essencial da educação no desenvolvimento contínuo, tanto das pessoas como das sociedades.Não como um"remédio milagroso", não como um "abre-te sésamo" de um mundo que atingiu a realização de todos os seus ideais mas, entre outros caminhos e para além deles, como uma via que conduza a um desenvolvimento humano mais harmonioso, mais autêntico, de modo a fazer recuar a pobreza, a exclusão social, as incompreensões, as opressões, as guerras...(DELORS et al.,2003, p. 11).
}

Nessa perspectiva, não podemos pensar o aluno só como o resultado de um currículo, como uma diretriz curricular que traça seu perfil profissional. É necessário pensar na formação do aluno como parte de uma política curricular que não se reduz a uma simples 
diretriz, a um documento que simboliza o discurso oficial do Estado, que agrega interesses diversos e alianças elaboradas a diversos níveis de ação.

As políticas curriculares no ensino precisam ser comprometidas com o futuro dos alunos enquanto cidadãos, capazes de serem partes de uma comunidade científica e compartilharem seus conhecimentos com a sociedade. As políticas curriculares devem estar direcionadas para formar cidadãos, ilimitados, autônomos, com ideias próprias, empreendedores, com sentimento de poder criar para o mundo. Com isso, teríamos alunos potencializados para o avanço da ciência e da tecnologia, como sujeitos comprometidos com o desenvolvimento humano.

\section{A Atuação dos Professores e dos Alunos como Decisores Políticos}

A efetivação das políticas curriculares se dá com a práxis dos atores durante o processo de ensino aprendizagem no espaço da escola e da comunidade. Organiza-se em torno dos conhecimentos que se edificam nas articulações estabelecidas entre os conhecimentos teóricos formais curriculares, adicionados à cultura e aos valores da comunidade em que está inserida a escola; assim, é necessário evocar uma atuação de participação na construção do currículo.

Quando professores e alunos convocam os conhecimentos formais curriculares adicionados à cultura e aos valores da comunidade, e analisam a importância deles nas suas práticas em favor da qualidade em suas vidas, passam a ser atuantes e decisores em suas aprendizagens,ressignificando as em suas experiências.

O envolvimento com a comunidade é um elemento importante na construção de uma prática reflexiva. Segundo Formosinho (2007, p.16), "Ser profissional reflexivo, é antes, durante e depois da ação, fecundar as práticas nas teorias e nos valores, interrogar para a ressignificar o já feito em nome da reflexão que constantemente o reinstitui".

Esse envolvimento, para Formosinho (2007, p.16), possibilita uma prática pedagógica construtivista: 
[...] que a apoiam a construção no quotidiano, de uma pedagogia da participação e que permita clarificar concepções, tomar decisões, sentir pertenças e, com isso, desenvolver um sentir, pensar e fazer pedagógico fortalecido, rico, texturado, menos dependente do aqui e agora, de um pressentimento redutor e limitado.

A interação do professor, do aluno e da comunidade permite para ambos um trabalho participativo que possibilita o estudo do ambiente escolar. Abre para escuta e observação do aluno e de todos os envolvidos no processo educativo. Permite um plano de trabalho capaz de investigar novas formas de aprendizagens em pequenos grupos, grandes grupos e individual. Pensamos esse processo como construtivista, embasados em teóricos, como Piaget (1998), Vygotsky (1988), Freinet (1973),Bruner (2001), entre tantos outros já conhecidos por todos os professores que passaram pelo ensino superior e pelas constantes formações continuadas oferecidas pelos municípios, estado, ou organizadas pela própria escola.

Esse processo construtivista está sendo construído, vagarosamente, em nossas escolas, assim, vemos que já se iniciou uma reflexão sobre as políticas curriculares nos espaços da escola, e que os efeitos dessas reflexões em proporção mínima já estão atingindo a sala de aula.

Nos últimos anos vêm ocorrendo mudanças nas práticas dos professores e dos alunos tanto no ensino superior, referente à formação inicial, quanto nas formações continuadas realizadas nas secretarias de educação municipais e estaduais. As inovações levam para uma educação mais construtivista e menos tecnicista.

Autores da formação de professores vêm chamando para essa reflexão há algum tempo. Tardif (2012) relata que as observações feitas por ele, em suas viagens pelas Américas, sobre as consequências políticas educacionais, apontam para duas ideias que podem contribuir para a melhoria na profissão docente:

[...] A primeira é que os professores só serão reconhecidos como sujeitos do conhecimento quando lhes concedermos, dentro do sistema escolar e dos estabelecimentos, o status de verdadeiros atores, e não o de simples técnicos ou de executores das reformas da educação concebidas com base numa lógica burocrática "top anddown". [...] Minha segunda ideia é a seguinte: Em todos os países que visitei nos últimos anos, pude observar, no âmbito da profissão docente, muitas divisões internas que geram lutas de poder e de prestigio, exclusões e ignorâncias recíprocas entre todas as pessoas que têm a missão de educar as novas gerações. (TARDIF, 2012, p. 243). 
Brandão (2008) também faz uma reflexão sobre as políticas públicas de formação inicial e continuada de professor, e, segundo ele, durante o governo de Fernando Henrique Cardoso, articula-se, a pedido do Banco Mundial, uma "formação em serviço e no aligeiramento da formação inicial, entendida como capacitação pedagógica de cunho estritamente técnico".

A implementação de políticas públicas de formação inicial e continuada dos professores é uma condição essencial para o desenvolvimento e avanço científico das tecnologias; sabe-se, também, que a formação inicial e continuada se torna cada vez mais necessária para os avanços científicos e tecnológicos. O que ocorre é que os professores e seus alunos estão se tornando escravos da técnica; precisa-se entender a complexidade desses avanços para que o desenvolvimento não seja totalmente econômico, mas que seja também para o desenvolvimento humano.

Neste sentido, as escolas precisam se reconstruir como um lugar de partilha de valores, cultura e conhecimentos, estabelecendo relações entre seus atores. A organização curricular precisa se envolver, na comunidade estruturada, em premissas que provoquem a interação, a comunicação, a colaboração, o comprometimento e faça sentido para os atores da escola.

\section{Considerações Finais}

Pedimos licença para fazer as considerações finais com base em um sentimento pessoal que ficou ao terminar a parte escrita deste texto. Durante a construção das ideias que foram se juntando, ao escrever o texto foi aparecendo o sentimento de "labuta", trabalhar com as ideias que envolvem as Políticas Curriculares que se Desdobram nos Espaços da Escola e na Formação de Professores é uma "tarefa que se realiza penosamente", por ser muito complexa.

São muitos os elementos que se tem que trazer para essa discussão: filosóficos, sociológicos, psicológicos, sociais, culturais, estruturais, econômicos etc. Estes elementos se confrontam com uma realidade,a realidade trazida pela política partidária do nosso país, em que não se dá continuidade às políticas de um governo para o outro. 
A descontinuidade das labutas educacionais em todos os níveis de educação, os financiamentos que são cortados no meio das tarefas ainda não concluídas, torna-se um desafio maior do que se imagina no caminhar para uma educação de qualidade e mais humana. A distância entre o que está nos documentos oficiais e o que acontece nas escolas é angustiante.

Trata-se de um processo demorado de muita "labuta" mesmo, e que exige muita persistência. As universidades, em suas formações iniciais de professores, e as secretarias, em suas formações continuadas, têm que insistir muito nos desvelamentos da política pública e continuidade de seus trabalhos.

Vale destacar que, nesse processo de conferir maior coerência e efetividade às políticas públicas curriculares, é necessário também intensificar forças na educação, para envolver a família e a comunidade na escola, fortalecer o uso de didáticas participativas, ampliar a oferta de espaços físicos que possibilitem múltiplas aprendizagens, aprimorar o trabalho cooperativo, entre outras.

Considerando que ainda há muito a ser respondido sobre a questão, as Políticas Curriculares que se Desdobram nos Espaços da Escola e na Formação de Professores, convida-se os leitores deste texto que aceitem o desafio de contribuírem com a promoção de políticas curriculares que sejam flexíveis, dinâmicas, participativas e coerentes com as realidades múltiplas dos ambientes educacionais.

\section{Referências}

BRANDÃO, Carlos da Fonseca. Política educacional e organização da educação brasileira. São Paulo: Cultura Acadêmica; Universidade Estadual Paulista;Pró-Reitoria de Graduação, 2008.

BRUNER, J. A cultura da educação. Porto Alegre: Artmed. 2001

DELORS, Jacques et al.Educação: um tesouro a descobrir. Relatório para a UNESCO da Comissão Internacional sobre Educação para o século XXI. Prefácio. 2. ed. São Paulo: Cortez;Brasília: MEC/UNESCO, 2003.

FREINET, C. As técnicas Freinet da Escola Moderna. Tradução: Silva Letra. Lisboa: Editorial Estampa, 1973. 
FORMOSINHO, Júlia Oliveira. (Org.).Modelos Curriculares para a Educação de Infância: Construindo uma práxis de participação.Porto, Portugal: Porto Editora, 2007.

PACHECO, José Augusto. Políticas Curriculares: referências para análise. Porto Alegre: Artmed, 2003.

PIAGET, J. A evolução social e a pedagogia nova. In: Sobre a pedagogia: textos inéditos. Org. e introd. S. Parrat-Dayan e A. Tryphon. São Paulo: Casa do Psicólogo, 1998.

TARDIF, Maurice. Saberes docentes e formação profissional. 14. ed. Petrópolis: Vozes, 2012.

VYGOTSKY, L.S. A formação social da mente. $2^{\mathrm{a}}$ ed. Brasileira. São Paulo: Martins Fontes, 1988.

Como citar este artigo (Formato ABNT):

SILVA, Raimundo Alves de Lira; CAFFÉ FILHO, Hesler PGABRIEL, Aparecida G.P.; FREIRE, Eduardo J.; CHAVES, Sidney da S.; ZENELLI, Marlize R.; DE JESUS, Marcelino; RIBEIRO, mariana E.O. As Políticas Curriculares que se desdobram nos espaços da Escola e na Formação de Professores. Id on Line Revista Multidisciplinar e de Psicologia, 2017, vol.11, n.37, p. 298-307. ISSN: 1981-1179.

Recebido: 25.08 .2017

Aceito: 26.08 .2017 